CrossMark <click for updates

Cite this: Soft Matter, 2016, 12,625

DOI: $10.1039 / \mathrm{c} 5 \mathrm{sm} 90197 \mathrm{a}$

www.rsc.org/softmatter

\section{Correction: Probing viscoelastic response of soft material surfaces at the nanoscale}

\author{
David B. Haviland, ${ }^{\star a}$ C. Anthony van Eysden, ${ }^{a}$ Daniel Forchheimer, ${ }^{a}$ Daniel Platz, ${ }^{a}$ \\ Hailu G. Kassa ${ }^{b}$ and Philippe Leclère ${ }^{b}$
}

Correction for 'Probing viscoelastic response of soft material surfaces at the nanoscale' by David B. Haviland et al., Soft Matter, 2015, DOI: 10.1039/c5sm02154e.

Table 1 contains an incorrectly captured value for the surface damping yellow. The value 24 should have read 0.24 . Please see below for the corrected table.

Table 1

\begin{tabular}{lllllll}
\hline & Surface stiffness & Surface damping & Interaction damping & Reduced modulus & \multicolumn{2}{c}{$\begin{array}{l}\text { Adhesion force } \\
F_{\text {adh }}[\mathrm{nN}]\end{array}$} \\
Color & $k_{\mathrm{s}}\left[\mathrm{N} \mathrm{m}^{-1}\right]$ & $\eta_{\mathrm{s}}\left[\mathrm{mg} \mathrm{s}^{-1}\right]$ & $\eta_{\mathrm{i}}\left[\mathrm{mg} \mathrm{s}^{-1}\right]$ & $\begin{array}{l}\text { Working distance } \\
h-z_{0}[\mathrm{~nm}]\end{array}$ \\
\hline Cyan & 1.000 & 47 & 0.71 & 3500.0 & 6.0 & 28.0 \\
Green & 0.100 & 28 & 0.13 & 40.0 & 2.0 & 18.0 \\
Yellow & 0.050 & 0.24 & 0.13 & 15.0 & 2.0 & 24.0
\end{tabular}

A low resolution version of the bottom half of Fig. 3 was published. Below is a higher resolution version.
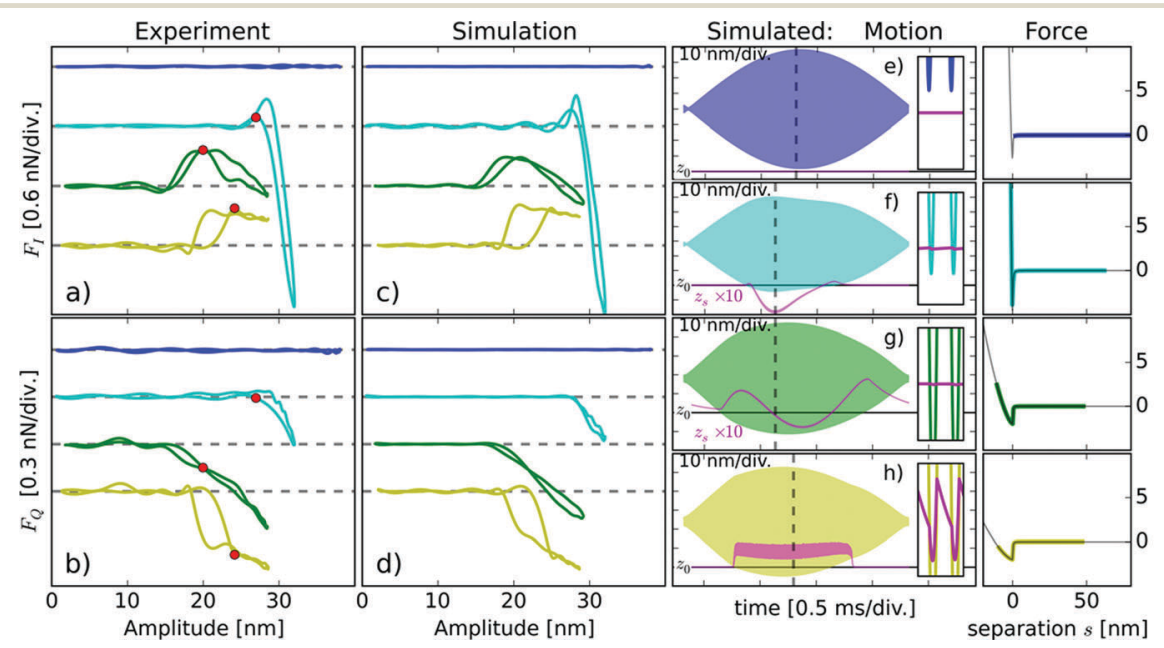

Fig. 3

The authors regret an error in one of the author names, C. Anthony van Eysden, in the original manuscript. The corrected list of authors for this paper is as shown above.

The Royal Society of Chemistry apologises for these errors and any consequent inconvenience to authors and readers.

\footnotetext{
${ }^{a}$ Nanostructure Physics and Nordita, Royal Institute of Technology (KTH), Roslagstullsbacken 21, SE-10691 Stockholm, Sweden. E-mail: haviland@kth.se

${ }^{b}$ Laboratory for Chemistry of Novel Materials, Center for Innovation and Research in Materials and Polymers, University of Mons (UMONS), Place du Parc 20,

B-7000 Mons, Belgium
} 